\title{
Research Article \\ Effect of Nd:YAG Low Level Laser Therapy on Human Gingival Fibroblasts
}

\author{
Andreas S. Gkogkos, Ioannis K. Karoussis, Ioannis D. Prevezanos, \\ Kleopatra E. Marcopoulou, Kyriaki Kyriakidou, and Ioannis A. Vrotsos
}

Department of Periodontology, School of Dentistry, University of Athens, 2 Thivon Street, Goudi, 11527 Athens, Greece

Correspondence should be addressed to Ioannis A. Vrotsos; ivrotsos@dent.uoa.gr

Received 13 May 2015; Revised 5 September 2015; Accepted 9 September 2015

Academic Editor: Yoshitaka Hara

Copyright (c) 2015 Andreas S. Gkogkos et al. This is an open access article distributed under the Creative Commons Attribution License, which permits unrestricted use, distribution, and reproduction in any medium, provided the original work is properly cited.

\begin{abstract}
Aim. To evaluate the effect of Low Level Laser Therapy (LLLT) on human gingival fibroblasts in terms of proliferation and growth factors' secretion (EGF, bFGF, and VEGF). Materials and Methods. Primary cultures of keratinized mucosa fibroblasts were irradiated by a Nd:YAG laser $1064 \mathrm{~nm}$ with the following energy densities: $2.6 \mathrm{~J} / \mathrm{cm}^{2}, 5.3 \mathrm{~J} / \mathrm{cm}^{2}, 7.9 \mathrm{~J} / \mathrm{cm}^{2}$, and $15.8 \mathrm{~J} / \mathrm{cm}^{2}$. Controls were not irradiated. Cultures were examined for cell proliferation and growth factors' secretion after 24, 48 , and 72 hours. All experimental procedures were performed in duplicate. Data were analyzed by Student's $t$-test $(p<0.05)$. Results. All laserirradiation doses applied promoted a higher cell proliferation at 48 hours in a dose-response relationship compared to controls. This difference reached statistical significance for the cultures receiving $15.8 \mathrm{~J} / \mathrm{cm}^{2}(p=0.03)$. Regarding EGF, all laser irradiation doses applied promoted a higher secretion at 48 hours in a reverse dose-response pattern compared to controls. This difference reached statistical significance for the cultures receiving $2.6 \mathrm{~J} / \mathrm{cm}^{2}(p=0.04)$. EGF levels at the other time points, bFGF, and VEGF showed a random variation between the groups. Conclusion. Within the limits of this study, LLLT (Nd:YAG) may induce gingival fibroblasts' proliferation and upregulate the secretion of EGF. Further studies are needed to confirm these results.
\end{abstract}

\section{Introduction}

Laser devices, almost 50 years after their introduction, find numerous applications in health sciences and are used successfully in several dental specialties. At a high output power, lasers cause thermomechanical ablation used for incisions and hard or soft tissue removal. However, at a low output power $(0.2-0.5 \mathrm{~W})$, referred to as Low Level Laser Therapy (LLLT), they may present a stimulatory effect, via a photobiologic phenomenon (photobiomodulation), promoting tissue healing, reducing inflammation, and inducing analgesia [1]. The exact biological mechanisms that explain LLLT's effect are still a matter of research.

It has been reported that irradiation with red or nearinfrared light can lead to the activation of mitochondrial respiratory chain components and the initiation of a signaling cascade which promotes mitosis and growth factors' secretion [2]. Growth factors represent keystones in the wound healing procedures. Specially, blood-derived fibroblast growth factor
(bFGF) has anti-inflammatory effect [3], vascular endothelial growth factor (VEGF) plays a role in angiogenesis, inflammation, and wound healing $[4,5]$, and epidermal growth factor (EGF) promotes a dose-dependent migratory response in gingival fibroblasts accelerating wound healing [6].

It has been shown that LLLT may influence the proliferation of various cells participating in oral wound healing process, such as gingival fibroblasts [7], gingival epithelial cells [8], periodontal ligament cells [9], osteoblasts [10], and bone mesenchymal stem cells [11]. Although several studies support the stimulating effect of LLLT on gingival fibroblasts, the vast majority of them used diode lasers [7, 12-14]. Literature data using neodymium-doped yttrium aluminum garnet (Nd:YAG) $1064 \mathrm{~nm}$ lasers are very rare. Additionally, the aforementioned studies present heterogeneity in terms of wavelengths, output powers, time of application, energy densities, and technical parameters such as the type of optical fiber and the distance between optical fiber and targeting cells. The determination of parameters that could optimize 
LLLT's impact on wound healing of periodontal tissues is very important. A positive upgrowth stimulation effect of LLLT on gingival fibroblasts could have clinical applications in both nonsurgical and surgical periodontal therapy.

Thus, the aim of this in vitro study was to evaluate the effect of various energy densities of LLLT, performed with a Nd:YAG laser (1064-nm) on human gingival fibroblasts in terms of cells' proliferation and specific growth factors' secretion (EGF, bFGF, and VEGF), at certain time points after irradiation.

\section{Materials and Methods}

2.1. Biopsy Collection. For the purpose of this in vitro study, connective tissue specimens were obtained by two healthy nonsmoking donors ( 1 female $30 \mathrm{ys,} 1$ male $30 \mathrm{ys}$ ). Biopsies were performed during second-stage implant surgeries at the Postgraduate Clinic, Department of Periodontology, National and Kapodistrian University of Athens. Immediately after flap elevation, $6 \times 6 \mathrm{~mm}$ specimens were collected from the connective tissue part of the flap. All tissue collections were carried out according to the approved guidelines set by the Human Ethics Board of Kapodistrian University of Athens, School of Dentistry.

2.2. Cell Cultures. Specimens were carefully sliced into $3 \mathrm{~mm}$ slides. Explants plated on $35 \mathrm{~mm}$ dishes, produced outgrowths composed of fibroblasts, after culture in Dulbecco's Modified Eagle's Medium (DMEM; Gibco Grand Island, NY) supplemented with $10 \%$ bovine calf serum (Grand Island, NY), $100 \mathrm{U} / \mathrm{mL}$ penicillin $\mathrm{G}$ sodium, $100 \mathrm{mg} / \mathrm{mL}$ streptomycin sulfate, and $250 \mathrm{pg} / \mathrm{mL}$ amphotericin B (Gibco, Grand Island, NY). The obtained fibroblasts grew on standard conditions $\left(37^{\circ} \mathrm{C}, 85 \%\right.$ humidity, and $\left.5 \% \mathrm{CO}_{2}\right)$. After the first passage (cells reached $80 \%-85 \%$ confluence), cultures were subjected to immunomagnetic cell sorting using STRO-1 (BioLegend, San Diego, CA, USA) and anti-IgM MicroBeads (Miltenyi Biotec, Bergisch Gladbach, Germany) according to the manufacturers' instructions (MACS; Miltenyi Biotec, Bergisch Gladbach, Germany), in order to determine the cells' type (fibroblasts). The experiment took place at the third passage. After cultures' growth, cells were trypsinized and seeded at 12 -well multiwall $\left(3.8 \mathrm{~cm}^{2}\right)$ plates $(10000$ cells/ $\mathrm{mL}$ ) in DMEM 10\% fetal bovine serum (FBS). Before laser irradiation the medium of samples and controls was completely removed and replaced with serum-free DMEM.

2.3. Laser Irradiation. The irradiation was performed with a Nd:YAG laser (1064-nm, DEKA Smart File) and a prefabricated, commercially available, handpiece (manipolo per terapia N40601). The laser beam was directed perpendicularly to the cell level from a distance of $5 \mathrm{~mm}$. Cells were irradiated for 20, 40, 60, or 120 seconds (Figure 1).

The irradiation settings were power $0.5 \mathrm{~W}$, frequency $10 \mathrm{~Hz}$, energy $50 \mathrm{~mJ}$, and pulse duration $\geq 700 \mu \mathrm{sec}$. The corresponding energy densities were $2.6 \mathrm{~J} / \mathrm{cm}^{2}, 5.3 \mathrm{~J} / \mathrm{cm}^{2}$, $7.9 \mathrm{~J} / \mathrm{cm}^{2}$, and $15.8 \mathrm{~J} / \mathrm{cm}^{2}$, respectively (Table 1 ). A wide range of energy densities was selected, to investigate all the possible

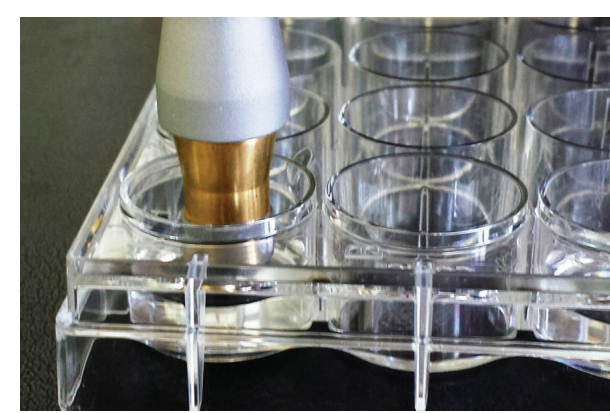

FIgURE 1: The irradiation was carried out with manipolo per terapia N4060 handpiece, approximately $5 \mathrm{~mm}$ above cell level.

TABLE 1: Laser parameters used during irradiation.

\begin{tabular}{|c|c|c|c|}
\hline Laser & \multicolumn{3}{|c|}{ Nd:YAG } \\
\hline Wavelength & \multicolumn{3}{|c|}{$1064 \mathrm{~nm}$} \\
\hline Spectrum & \multicolumn{3}{|c|}{ Near-infrared } \\
\hline $\begin{array}{l}\text { Irradiation } \\
\text { mode }\end{array}$ & \multicolumn{3}{|c|}{ Pulsed wave, long pulse ( $\geq 700 \mu \mathrm{sec})$} \\
\hline Settings & \multicolumn{3}{|c|}{ Power $0,5 \mathrm{~W}$, frequency $10 \mathrm{~Hz}$, and energy $50 \mathrm{~mJ}$} \\
\hline Duration & $40 \mathrm{~s}$ & $60 \mathrm{~s}$ & $120 \mathrm{~s}$ \\
\hline Energy density & $2.6 \mathrm{~J} / \mathrm{cm}^{2} 5.3 \mathrm{~J} / \mathrm{cm}^{2}$ & $7.9 \mathrm{~J} / \mathrm{cm}^{2}$ & $15.8 \mathrm{~J} / \mathrm{cm}^{2}$ \\
\hline Irradiation & \multicolumn{3}{|c|}{ Single treatment at day 0} \\
\hline Spot area & \multicolumn{3}{|c|}{$0,785 \mathrm{~cm}^{2}$ (manipolo per terapia N40601) } \\
\hline $\begin{array}{l}\text { Distance of } \\
\text { irradiation }\end{array}$ & \multicolumn{3}{|c|}{$5 \mathrm{~mm}$} \\
\hline
\end{tabular}

effects of LLLT with Nd:YAG laser on gingival fibroblasts, either positive or negative. Control cultures were not irradiated. All experiments were performed in duplicate.

2.4. Proliferation Assessment. Cells were counted after trypsinization (0,05\% trypsin/EDTA in PBS for 5 minutes) at day 0 (baseline levels), 24, 48, and 72 hours after irradiation for both irradiated and control groups. The proliferation was assessed with an optical method. In an inverted optical microscope (Zeis), cell counting was performed over a hemocytometer, by an experienced blinded (the examiner was not aware of the treatment for each culture) biologist.

2.5. Growth Factors Assay. Growth factors' secretion was assessed with Luminex technology. Luminex's xMAP technology is based on a combination of flow cytometry, microspheres, lasers, digital signal processing, and traditional chemistry. The technique involves Luminex's 100 distinct sets of tiny color-coded beads, called microspheres. Each bead set can be coated with a specific capture probe or Anti Tag to allow the capture and detection of specific targets. The technology allows rapid and precise analysis of several protein molecules, within a single reaction.

Supernatants were collected at day 0 (baseline levels), 24, 48, and 72 hours after irradiation. A quantitative analysis of EGF, bFGF, and VEGF levels was performed, according to the 


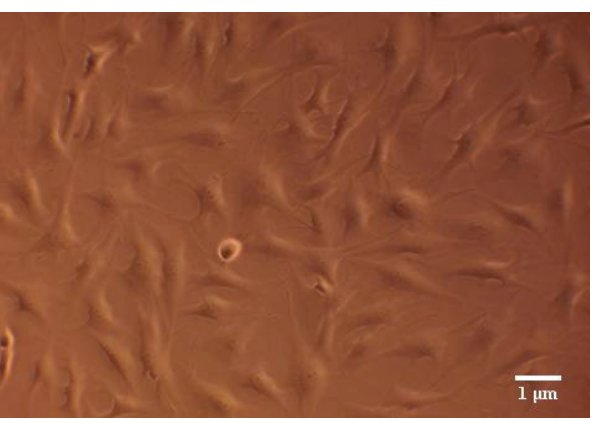

(a)

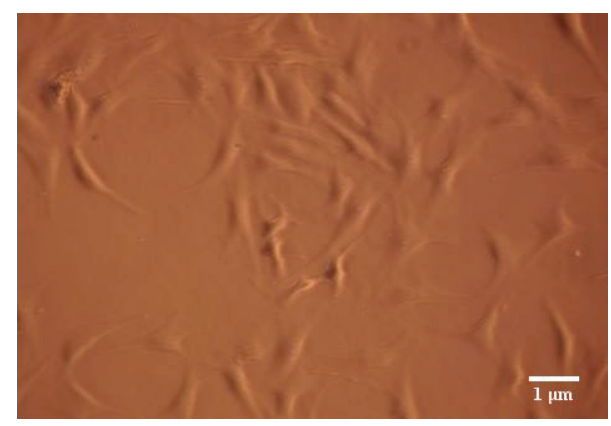

(b)

FIGURE 2: Human gingival fibroblasts at 48 hours. (a) Irradiated with Nd:YAG laser for 120 (120 s group) (original magnification, $\times 100$ ). (b) Nonirradiated (Ctrl group), (original magnification, $\times 100$ ).

TABLE 2: Cell counts of control and test groups for the different time points.

\begin{tabular}{|c|c|c|c|c|}
\hline Cells & $N$ & Mean (SD) & Median (range) & $p$ value $^{*}$ \\
\hline \multicolumn{5}{|c|}{24 hours } \\
\hline Controls & 4 & $39500(10116)$ & $41000(28000,48000)$ & \\
\hline $20 s$ & 4 & $35250(8382)$ & $37000(24000,43000)$ & 0.54 \\
\hline $40 \mathrm{~s}$ & 4 & 37000 (11605) & $38000(22000,50000)$ & 0.76 \\
\hline $60 \mathrm{~s}$ & 4 & 41000 (13216) & $40000(26000,58000)$ & 0.86 \\
\hline $120 \mathrm{~s}$ & 4 & $38750(8539)$ & $37500(30000,50000)$ & 0.91 \\
\hline \multicolumn{5}{|c|}{48 hours } \\
\hline Controls & 4 & $44000(15144)$ & $38000(34000,66000)$ & \\
\hline $20 s$ & 4 & $45500(5972)$ & $44000(40000,54000)$ & 0.86 \\
\hline $40 \mathrm{~s}$ & 4 & 51500 (9849) & $51000(40000,64000)$ & 0.43 \\
\hline $60 \mathrm{~s}$ & 4 & $61500(5972)$ & $60000(56000,70000)$ & 0.07 \\
\hline $120 \mathrm{~s}$ & 4 & $68000(6325)$ & $69000(60000,74000)$ & 0.03 \\
\hline \multicolumn{5}{|c|}{72 hours } \\
\hline Controls & 4 & $72750(10500)$ & $69500(64000,88000)$ & \\
\hline $20 s$ & 4 & $58000(17205)$ & $57000(40000,78000)$ & 0.19 \\
\hline $40 \mathrm{~s}$ & 4 & $79500(22531)$ & $81000(52000,104000)$ & 0.60 \\
\hline $60 \mathrm{~s}$ & 4 & $81500(13796)$ & $83000(64000,96000)$ & 0.35 \\
\hline $120 \mathrm{~s}$ & 4 & $83500(17388)$ & $86000(60000,102000)$ & 0.33 \\
\hline
\end{tabular}

${ }^{*}$ Versus control.

manufactures' recommendations (Luminex Human Growth Factor 4-plex Panel Kit, Invitrogen, CA).

2.6. Statistical Analysis. To investigate differences in cells' number between each test group and controls, we used Student's t-test. For the comparison of growth factors (EGF, VEGF, and bFGF) we first calculated the change from the baseline measurement for each group and we compared those changes using $t$-test, at every time point. All tests were twosided at $\alpha=5 \%$ level of statistical significance.

\section{Results}

All laser-irradiation doses applied promoted a higher cell proliferation at 48 hours compared to control group. This difference reached statistical significance for the group irradiated for $120 \mathrm{~s}$ versus control group (mean: 68000, SD:
6324.555, 95\% CI: 57936.22-78063.78, and $p=0.03$ ) (Figures 2(a) and 2(b)).

A dose-response relationship, at $48 \mathrm{~h}$ may be implied. At 72 hours, all laser-irradiated groups (except $20 \mathrm{~s}$ ) cells' number was higher than controls. The growth curves are shown in Table 2 and Figure 4.

Growth factors' secretion results are presented in Table 3. Regarding EGF, all laser-irradiation doses applied promoted a higher secretion at 48 hours compared to control group. This difference reached statistical significance for the group irradiated for $20 \mathrm{~s}$ versus control group (mean: 16.7, SD: 5.608923, 95\% CI: 7.774953-25.62505, and $p=0.04$ ) (Figure 3). A reverse dose-response relationship, at $48 \mathrm{~h}$, may be implied. As far as VEGF, at $48 \mathrm{~h}$, values were higher or equal to controls. EGF and VEGF values, at the other time points (24 and 72 hours) and bFGF as well, showed a random variation between the groups. 
TABLE 3: Mean (SD) change from the baseline measurement for each group at every time point.

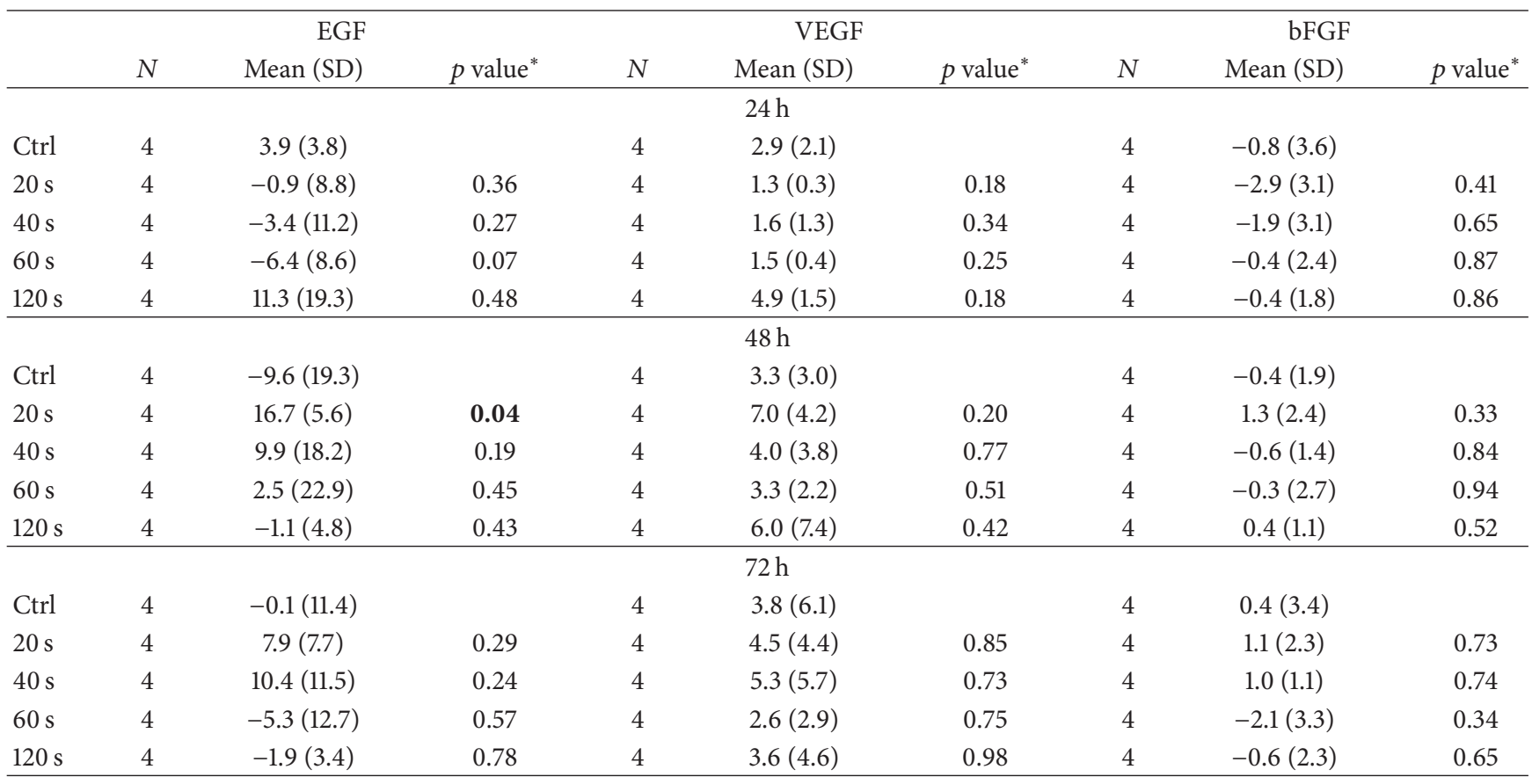

${ }^{*} t$-test versus control.

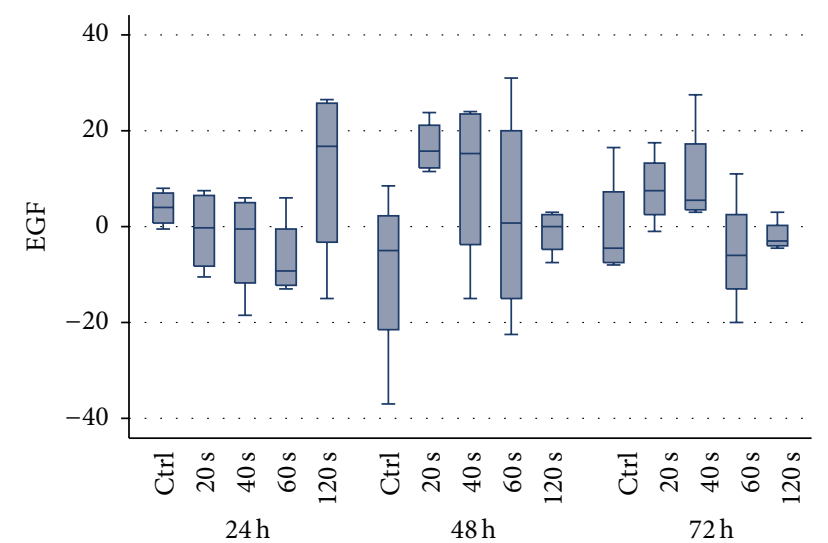

Figure 3: Boxplot of EGF values differences from baseline for each radiation time and control, after 24,48 , and 72 hours.

\section{Discussion}

4.1. LLLT and Cells Proliferation. Within the limitations of this study (sample size and arbitrary energy densities), it appeared that treatment with low power laser (LLLT) using Nd:YAG laser, specifically in irradiation time of $120 \mathrm{~s}$ (energy density: $15.8 \mathrm{~J} / \mathrm{cm}^{2}$ ), resulted in a statistically significant increase of cells' population $(p=0.03$ ), compared to the control group, 48 hours after irradiation. In the international literature, some publications on the effect of laser devices on gingival fibroblasts, skin fibroblasts, and animal fibroblasts can be found [3, 15-19]. The heterogeneity, among these studies, regarding the type of laser devices used and their settings (wavelength, energy density), does not allow a direct

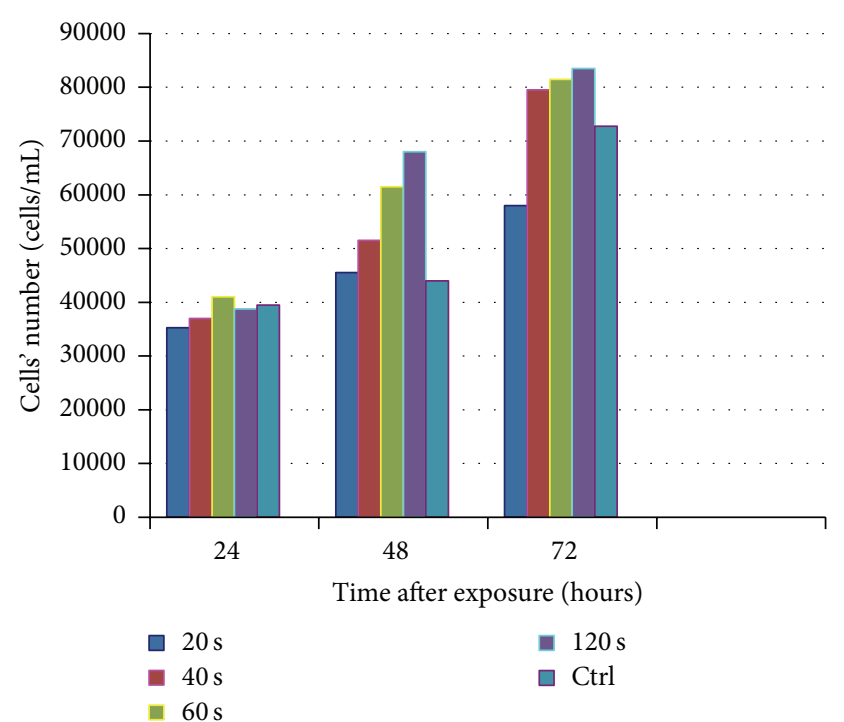

FIgURE 4: Cells' number of control and test groups 24, 48, and 72 hours after irradiation.

comparison between them and exportation of a detailed conclusion. However, it is generally supported, in most of the studies, that LLLT increases the cell population of gingival fibroblasts [7, 13, 20-22]. A recent systematic review, about the effect of LLLT in various human and animal cell cultures, showed the ability of laser to modulate cellular proliferation. However, finding the most appropriate irradiation settings is still an important piece of research [23].

It is worth mentioning that there is no equivalent study in the literature, concerning the settings of Nd:YAG laser and 
irradiation time. However, three studies researched the effect of Nd:YAG laser on gingival fibroblasts [15-17]. Specifically, Chen et al., in 2000, noticed evidence of a decrease in the vitality of human gingival fibroblasts (cell damage zone 2.2 $4.2 \mathrm{~mm}$ in diameter), after irradiation (1.0-3.0 W), for $10 \mathrm{sec}$. However, when defocused irradiation was applied $(2 \mathrm{~mm}$ from the cell level), no significant decrease in cell vitality was observed. The main difference between Chen's study and ours is the irradiation power $(1-3 \mathrm{~W}$ versus $0.5 \mathrm{~W})$. It seems that these power values cause cells' death. Furthermore, Chen et al. used a $400 \mu \mathrm{m}$ diameter fiber in contact or in $2 \mathrm{~mm}$ distance from cell level, in contrast with the present study, where a defocused handpiece (which ensured a uniform distribution of radiation on cells across the surface of the well) from the distance of $5 \mathrm{~mm}$ was used. Possibly the minus spot size (increased energy density) led to cells' death [15]. Moreover, Gutknecht et al. reported cellular (L-929 fibroblast cell cultures) damage with a necrotic zone of $8.1 \sim 10.0 \mathrm{~mm}$ in diameter after Nd:YAG laser irradiation $(2.1 \sim 3.0 \mathrm{~W})$ for 30 seconds [16]. It is obvious that at these two studies examined the possible hazard effect of Nd:YAG laser irradiation on gingival fibroblasts' vitality. In our study, the aim was to investigate the possible beneficial effects of $\mathrm{Nd}$ :YAG laser, using low level settings.

In another in vitro study, in skin fibroblasts, it appeared that the application of the Nd:YAG laser and KTP laser at high doses $\left(10-40 \mathrm{~J} / \mathrm{cm}^{2}\right.$ and $3-12 \mathrm{~J} / \mathrm{cm}^{2}$, resp.) resulted in structural damage to the DNA of cells [24]. In corresponding results, Hawkins and Abrahamse using high doses of irradiation with a HeNe laser (632.8-nm) observed a deterioration of structural components of the membrane and the DNA of the cells. They showed better results in skin fibroblasts' proliferation and migration after irradiation with HeNe laser (632.8-nm), relative to the diode $830 \mathrm{~nm}$ and Nd:YAG $(1064 \mathrm{~nm})$ (irradiation with $5 \mathrm{~J} / \mathrm{cm}^{2}$ on the first and fourth day) [25].

The other study, using Nd:YAG laser for LLLT $\left(1.5 \mathrm{~J} / \mathrm{cm}^{2}\right)$, was from Chellini et al. in 2010, who showed that fibroblasts' (cell line derived from mice NIH/3T3 fibroblasts) irradiation did not alter the vitality of cells, but it did not enhance cell proliferation too, 24 and 48 hours after irradiation. Instead, LLLT resulted in significant production of type I collagen. Results indicated the possible regulator role of LLLT with Nd:YAG laser in this particular cell culture [17]. Between this study and ours are many differences (primary culture versus cell line, frequency, energy, optic fiber diameter, time, and distance of irradiation), so a direct comparison cannot be implied. However, regarding energy densities $\left(1.5 \mathrm{~J} / \mathrm{cm}^{2}\right.$ versus 2.6 to $15.8 \mathrm{~J} / \mathrm{cm}^{2}$ ), it can be postulated that energy densities higher than $2.6 \mathrm{~J} / \mathrm{cm}^{2}$ should be used in LLLT with $\mathrm{Nd}$ :YAG laser to achieve gingival fibroblast proliferation.

In literature, there are studies using other laser wavelengths in LLLT. Specifically, Kreisler et al. found a statistically significant difference in gingival fibroblasts proliferation, 24 and 48 hours after irradiation with a diode laser $(809 \mathrm{~nm}$, $7.84 \mathrm{~J} / \mathrm{cm}^{2}$ ) [26]. The same biostimulatory effect of LLLT in gingival fibroblasts in in vitro studies was found by Basso et al. in 2012 with a diode laser $\left(780 \pm 3 \mathrm{~nm}, 0.5\right.$ and $\left.3 \mathrm{~J} / \mathrm{cm}^{2}\right)$ [13],
Vinck et al. in 2003 with a diode laser $\left(830 \mathrm{~nm}, 1 \mathrm{~J} / \mathrm{cm}^{2}\right)$ [27], Azevedo et al. in 2006 with a diode laser $\left(660 \mathrm{~nm}, 2 \mathrm{~J} / \mathrm{cm}^{2}\right)$ [7], and Pourzarandian et al. in 2005 with a Er:YAG laser $\left(3.37 \mathrm{~J} / \mathrm{cm}^{2}\right)[20]$.

4.2. LLLT and Growth Factors' Secretion. In this study, we found that all laser-irradiation doses applied promoted a higher secretion of EGF, at 48 hours, compared to control group. This difference reached statistical significance for the group irradiated for $20 \mathrm{~s}$ versus the control group $(p=0.04)$. A reverse dose-response relationship, at $48 \mathrm{~h}$, may be implied. Potentially, this trend exists, in the other groups, like VEGF at $48 \mathrm{~h}$, where all laser-irradiated group's values of VEGF were higher or equal to controls. However, due to the small sample, this claim remains to be confirmed by future studies. EGF and VEGF values at the other time points ( 24 and 72 hours) and bFGF as well showed a random variation between the groups.

It should be emphasized that in the literature there is no study to date to examine the secretion of EGF and VEGF from gingival fibroblasts after irradiation with Nd:YAG laser. The only relative reference is EGF secretion and LLLT, done by Mvula et al. in 2009, who studied the synergistic action of the growth factor with LLLT $(636 \mathrm{~nm}$, diode laser), which led to the proliferation of stem cells of adipose tissue [28].

In an experimental study on gingival fibroblast culture, it was found that irradiation with diode laser caused increased production of VEGF and TGF-b mRNA and the corresponding mRNA for the synthesis of type I collagen [29]. Also, Kipshidze et al., in 2001, showed that LLLT (He:Ne, $632 \mathrm{~nm}$, $2.1 \mathrm{~J} / \mathrm{cm}^{2}$ ) resulted in a statistically significant increase of VEGF secretion in culture of myocardium fibroblasts [30]. Dourado et al. in 2011, in an in vitro study in endothelial and nonendothelial cells of mice gastrocnemius, showed that LLLT with HeNe $(632.8 \mathrm{~nm})$ or GaAs $(904 \mathrm{~nm})$ laser increased angiogenesis and the proliferation of regenerating cells and decreased polymorphonuclear neutrophils [31]. Furthermore, in an in vivo animal (rat) study, it was found that LLLT with diode laser radiation in two different lengths (with energy density of 35 and $5 \mathrm{~J} / \mathrm{cm}^{2}$, resp.) resulted in a statistically significant reduction of expression of mRNA transcripting VEGF, after injury of the rats' tongue [32]. These data suggest that LLLT accelerates wound healing.

In the present study, no difference was observed in the secretion of bFGF between groups. Safavi et al. in 2008 led to similar results while LLLT with $\mathrm{HeNe}$ laser $\left(7.51 \mathrm{~J} / \mathrm{cm}^{2}\right)$ in mice gingiva showed a statistically significant increase in secretion of PDGF and TGF-b genes, 30 minutes after irradiation, but no influence to bFGF [3]. Indeed, Hawkins and Abrahamse reported that LLLT with Nd:YAG laser $\left(1064 \mathrm{~nm}, 16 \mathrm{~J} / \mathrm{cm}^{2}\right)$ resulted in reduced secretion of TGF-b $(p \leq 0.05)$. In contrast, irradiation with HeNe laser (632.8$\mathrm{nm}, 5 \mathrm{~J} / \mathrm{cm}^{2}$ ) resulted in marginally significant increase in secretion of bFGF ( $p=0.05)$ [25]. Moreover, Saygun et al. found a statistical significance $(p \leq 0.01)$ in bFGF expression after irradiation with a diode laser $\left(685 \mathrm{~nm}\right.$ for $\left.140 \mathrm{~s}, 2 \mathrm{~J} / \mathrm{cm}^{2}\right)$ [21]. Damante et al. concluded similar results in an in vitro study with a diode laser $\left(660 \mathrm{~nm}, 3 \mathrm{~J} / \mathrm{cm}^{2}\right.$ and $\left.5 \mathrm{~J} / \mathrm{cm}^{2}\right)$ [14]. Finally, it has been showed that LLLT with KTP laser $(532 \mathrm{~nm}$, 
$0.8 \mathrm{~J} / \mathrm{cm}^{2}$ ) in human skin fibroblasts led to statistically significant increase of bFGF gene expression [18]. These studies show that LLLT with diode laser, KTP, or HeNe laser possibly have an advantage compared to Nd:YAG laser, concerning bFGF secretion. On the other hand, Usumez et al. in an animal study found that Nd:YAG and $980 \mathrm{~nm}$ diode laser therapy $\left(8 \mathrm{~J} / \mathrm{cm}^{2}\right)$ accelerated the wound healing process by changing the expression of PDGF and bFGF [33].

Finally it is transpired that LLLT with Nd:YAG laser, at the settings used in this study (energy densities 2.6 to $15.8 \mathrm{~J} / \mathrm{cm}^{2}$ ), promoted both keratinized mucosa fibroblasts' proliferation and EGF secretion, 48 hours after irradiation. It could be postulated that a repetition of LLLT (with Nd:YAG laser) every 48 hours could possibly induce growth factors' secretion and cells proliferation after each irradiation.

\section{Conclusion}

Within the limitations of this experimental study (sample size and arbitrary energy densities), the results indicated that LLLT (Nd:YAG 1064 laser) did not cause cell death for the settings used. It appears that these settings of Nd:YAG laser are safe. Moreover, the cell proliferation of primary cultured gingival fibroblasts increased after laser irradiation, presenting a potentially dose-dependent action. LLLT (Nd:YAG, 1064 laser) contributes probably to the secretion of EGF in a reverse dose-response pattern. Finally, it becomes clear that more studies with larger sample sizes are needed, in order to draw solid conclusions. Future studies should consider evaluating growth factors, irradiation parameters, and/or laser wavelengths.

\section{Conflict of Interests}

The authors declare that there is no conflict of interests regarding the publication of this paper.

\section{Acknowledgment}

This study was funded by the authors.

\section{References}

[1] J. D. Carroll, M. R. Milward, P. R. Cooper, M. Hadis, and W. M. Palin, "Developments in low level light therapy (LLLT) for dentistry," Dental Materials, vol. 30, no. 5, pp. 465-475, 2014.

[2] X. Gao and D. Xing, "Molecular mechanisms of cell proliferation induced by low power laser irradiation," Journal of Biomedical Science, vol. 16, no. 1, article 4, 2009.

[3] S. M. Safavi, B. Kazemi, M. Esmaeili, A. Fallah, A. Modarresi, and M. Mir, "Effects of low-level He-Ne laser irradiation on the gene expression of IL- $1 \beta$, TNF- $\alpha$, IFN- $\gamma$, TGF- $\beta$, bFGF, and PDGF in rat's gingiva," Lasers in Medical Science, vol. 23, no. 3, pp. 331-335, 2008.

[4] J. E. Janis, R. K. Kwon, and D. H. Lalonde, "A practical guide to wound healing," Plastic and Reconstructive Surgery, vol. 125, no. 6, pp. 230e-244e, 2010.
[5] D. I. R. Holmes and I. C. Zachary, "Vascular endothelial growth factor regulates stanniocalcin-1 expression via neuropilin-1dependent regulation of KDR and synergism with fibroblast growth factor-2," Cellular Signalling, vol. 20, no. 3, pp. 569-579, 2008.

[6] F. Nishimura and V. P. Terranova, "Comparative study of the chemotactic responses of periodontal ligament cells and gingival fibroblasts to polypeptide growth factors," Journal of Dental Research, vol. 75, no. 4, pp. 986-992, 1996.

[7] L. H. Azevedo, F. de Paula Eduardo, M. S. Moreira, C. de Paula Eduardo, and M. M. Marques, "Influence of different power densities of LILT on cultured human fibroblast growth: a pilot study," Lasers in Medical Science, vol. 21, no. 2, pp. 86-89, 2006.

[8] K. Ejiri, A. Aoki, Y. Yamaguchi, M. Ohshima, and Y. Izumi, "High-frequency low-level diode laser irradiation promotes proliferation and migration of primary cultured human gingival epithelial cells," Lasers in Medical Science, vol. 29, no. 4, pp. 13391347, 2014.

[9] J.-Y. Wu, C.-H. Chen, L.-Y. Yeh, M.-L. Yeh, C.-C. Ting, and Y.-H. Wang, "Low-power laser irradiation promotes the proliferation and osteogenic differentiation of human periodontal ligament cells via cyclic adenosine monophosphate," International Journal of Oral Science, vol. 5, no. 2, pp. 85-91, 2013.

[10] V. Aleksic, A. Aoki, K. Iwasaki et al., "Low-level Er:YAG laser irradiation enhances osteoblast proliferation through activation of MAPK/ERK," Lasers in Medical Science, vol. 25, no. 4, pp. 559-569, 2010.

[11] J. Wang, W. Huang, Y. Wu et al., "MicroRNA-193 pro-proliferation effects for bone mesenchymal stem cells after low-level laser irradiation treatment through inhibitor of growth family, member 5," Stem Cells and Development, vol. 21, no. 13, pp. 2508-2519, 2012.

[12] W. Lim, J. Kim, S. Kim et al., "Modulation of lipopolysaccharide-induced NF- $\kappa$ B signaling pathway by $635 \mathrm{~nm}$ irradiation via heat shock protein 27 in human gingival fibroblast cells," Photochemistry and Photobiology, vol. 89, no. 1, pp. 199-207, 2013.

[13] F. G. Basso, T. N. Pansani, A. P. S. Turrioni, V. S. Bagnato, J. Hebling, and C. A. De Souza Costa, "In vitro wound healing improvement by low-level laser therapy application in cultured gingival fibroblasts," International Journal of Dentistry, vol. 2012, Article ID 719452, 6 pages, 2012.

[14] C. A. Damante, G. De Micheli, S. P. H. Miyagi, I. S. Feist, and M. M. Marques, "Effect of laser phototherapy on the release of fibroblast growth factors by human gingival fibroblasts," Lasers in Medical Science, vol. 24, no. 6, pp. 885-891, 2009.

[15] Y. J. Chen, J. H. Jeng, B. S. Lee, H. F. Chang, K. C. Chen, and W. H. Lan, "Effects of Nd:YAG laser irradiation on cultured human gingival fibroblasts," Lasers in Surgery and Medicine, vol. 27, no. 5, pp. 471-478, 2000.

[16] N. Gutknecht, S. Kanehl, A. Moritz, C. Mittermayer, and F. Lampert, "Effects of Nd:YAG-laser irradiation on monolayer cell cultures," Lasers in Surgery and Medicine, vol. 22, no. 1, pp. 30-36, 1998.

[17] F. Chellini, C. Sassoli, D. Nosi et al., "Low pulse energy Nd:YAG laser irradiation exerts a biostimulative effect on different cells of the oral microenvironment: 'an in vitro study,' Lasers in Surgery and Medicine, vol. 42, no. 6, pp. 527-539, 2010.

[18] V. K. M. Poon, L. Huang, and A. Burd, "Biostimulation of dermal fibroblast by sublethal Q-switched Nd:YAG $532 \mathrm{~nm}$ 
laser: collagen remodeling and pigmentation," Journal of Photochemistry and Photobiology B: Biology, vol. 81, no. 1, pp. 1-8, 2005.

[19] Y. Weng, Y. Dang, X. Ye, N. Liu, Z. Zhang, and Q. Ren, "Investigation of irradiation by different nonablative lasers on primary cultured skin fibroblasts," Clinical and Experimental Dermatology, vol. 36, no. 6, pp. 655-660, 2011.

[20] A. Pourzarandian, H. Watanabe, S. M. P. M. Ruwanpura, A. Aoki, and I. Ishikawa, "Effect of low-level Er:YAG laser irradiation on cultured human gingival fibroblasts," Journal of Periodontology, vol. 76, no. 2, pp. 187-193, 2005.

[21] I. Saygun, S. Karacay, M. Serdar, A. U. Ural, M. Sencimen, and B. Kurtis, "Effects of laser irradiation on the release of basic fibroblast growth factor (bFGF), insulin like growth factor-1 (IGF-1), and receptor of IGF-1 (IGFBP3) from gingival fibroblasts," Lasers in Medical Science, vol. 23, no. 2, pp. 211-215, 2008.

[22] I. S. Feist, G. De Micheli, S. R. S. Carneiro, C. P. Eduardo, S. P. H. Miyagi, and M. M. Marques, "Adhesion and growth of cultured human gingival fibroblasts on periodontally involved root surfaces treated by Er:YAG laser," Journal of Periodontology, vol. 74, no. 9, pp. 1368-1375, 2003.

[23] P. V. Peplow, T.-Y. Chung, and G. D. Baxter, "Laser photobiomodulation of proliferation of cells in culture: a review of human and animal studies," Photomedicine and Laser Surgery, vol. 28, no. 1, pp. S3-S40, 2010.

[24] N. Senturk, A. Bedir, B. Bilgici et al., "Genotoxic effects of 1064-nm Nd:YAG and 532-nm KTP lasers on fibroblast cell cultures: experimental dermatology," Clinical and Experimental Dermatology, vol. 35, no. 5, pp. 516-520, 2010.

[25] D. H. Hawkins and H. Abrahamse, "Time-dependent responses of wounded human skin fibroblasts following phototherapy," Journal of Photochemistry and Photobiology B: Biology, vol. 88, no. 2-3, pp. 147-155, 2007.

[26] M. Kreisler, A. B. Christoffers, H. Al-Haj, B. Willershausen, and B. D'Hoedt, "Low level 809-nm diode laser-induced in vitro stimulation of the proliferation of human gingival fibroblasts," Lasers in Surgery and Medicine, vol. 30, no. 5, pp. 365-369, 2002.

[27] E. M. Vinck, B. J. Cagnie, M. J. Cornelissen, H. A. Declercq, and D. C. Cambier, "Increased fibroblast proliferation induced by light emitting diode and low power laser irradiation," Lasers in Medical Science, vol. 18, no. 2, pp. 95-99, 2003.

[28] B. Mvula, T. J. Moore, and H. Abrahamse, "Effect of low-level laser irradiation and epidermal growth factor on adult human adipose-derived stem cells," Lasers in Medical Science, vol. 25, no. 1, pp. 33-39, 2010.

[29] S. S. I. Hakki and S. B. Bozkurt, "Effects of different setting of diode laser on the mRNA expression of growth factors and type i collagen of human gingival fibroblasts," Lasers in Medical Science, vol. 27, no. 2, pp. 325-331, 2012.

[30] N. Kipshidze, V. Nikolaychik, M. H. Keelan et al., "Low-power helium: neon laser irradiation enhances production of vascular endothelial growth factor and promotes growth of endothelial cells in vitro," Lasers in Surgery and Medicine, vol. 28, no. 4, pp. 355-364, 2001.

[31] D. M. Dourado, S. Fávero, R. Matias, P. D. T. C. Carvalho, and M. A. Da Cruz-Höfling, "Low-level laser therapy promotes vascular endothelial growth factor receptor-1 expression in endothelial and nonendothelial cells of mice gastrocnemius exposed to snake venom," Photochemistry and Photobiology, vol. 87, no. 2, pp. 418-426, 2011.
[32] T. C. Silva, T. M. Oliveira, V. T. Sakai et al., "In vivo effects on the expression of vascular endothelial growth factor- $\mathrm{A}_{165}$ messenger ribonucleic acid of an infrared diode laser associated or not with a visible red diode laser," Photomedicine and Laser Surgery, vol. 28, no. 1, pp. 63-68, 2010.

[33] A. Usumez, B. Cengiz, S. Oztuzcu, T. Demir, M. H. Aras, and N. Gutknecht, "Effects of laser irradiation at different wavelengths $(660,810,980$, and $1,064 \mathrm{~nm})$ on mucositis in an animal model of wound healing," Lasers in Medical Science, vol. 29, no. 6, pp. 1807-1813, 2014. 


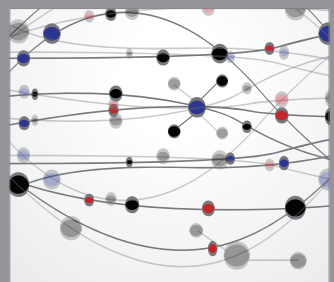

The Scientific World Journal
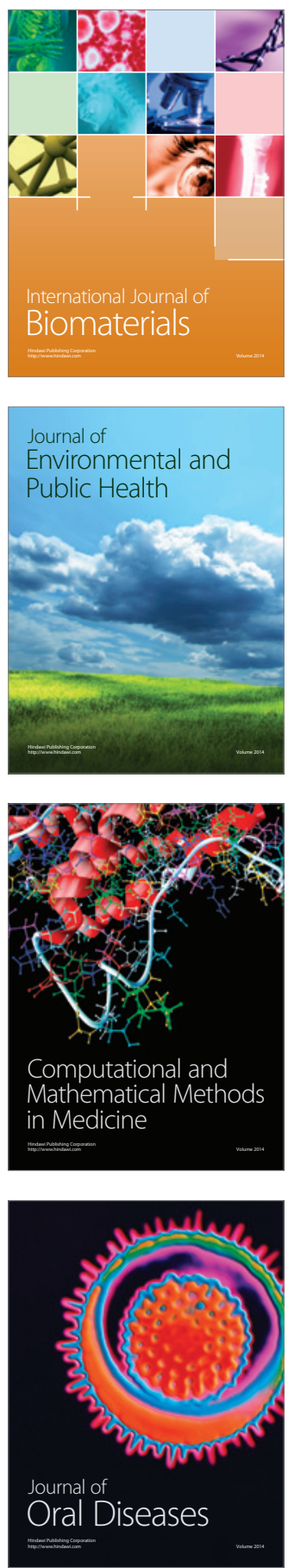
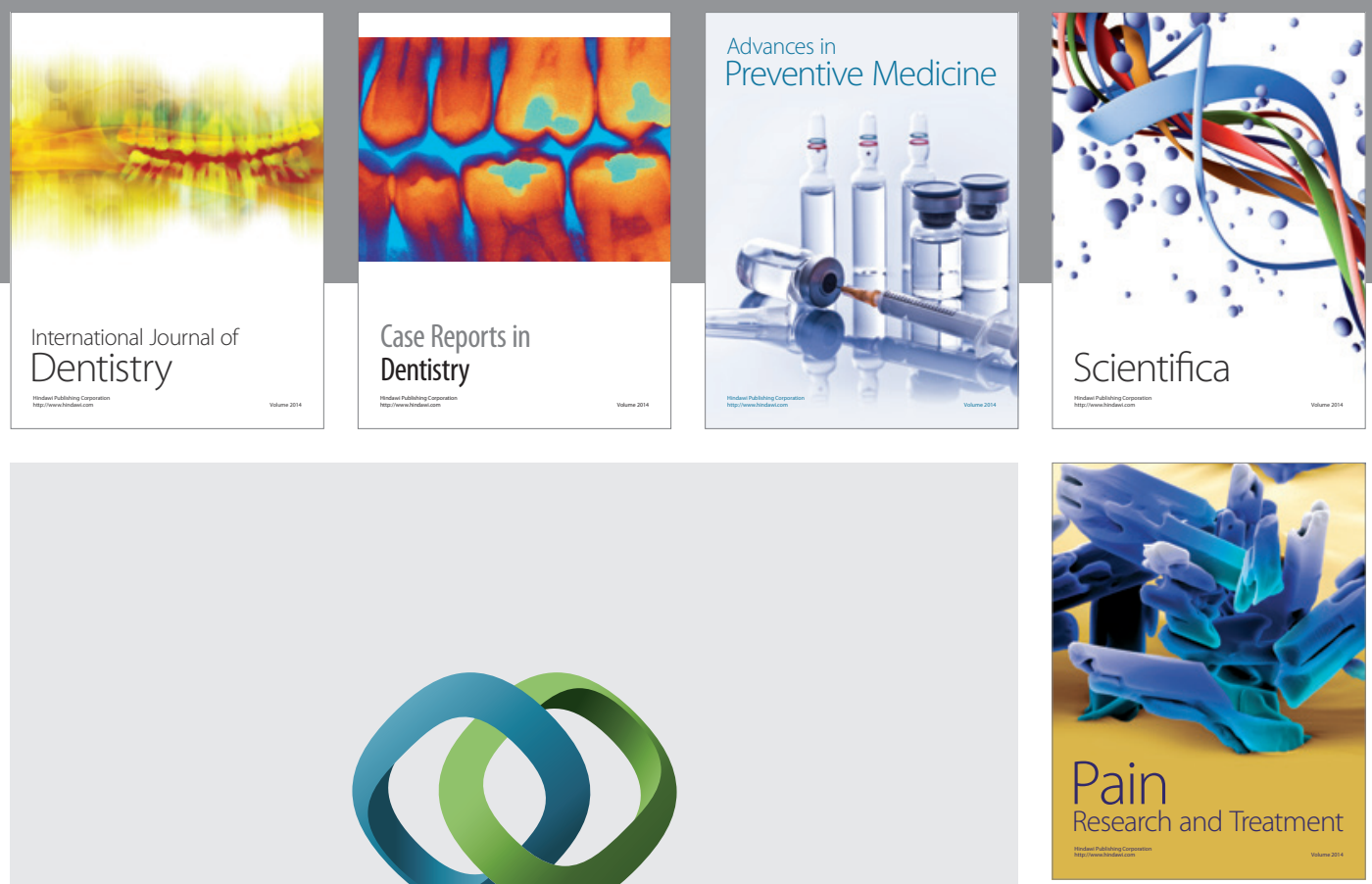

\section{Hindawi}

Submit your manuscripts at

http://www.hindawi.com
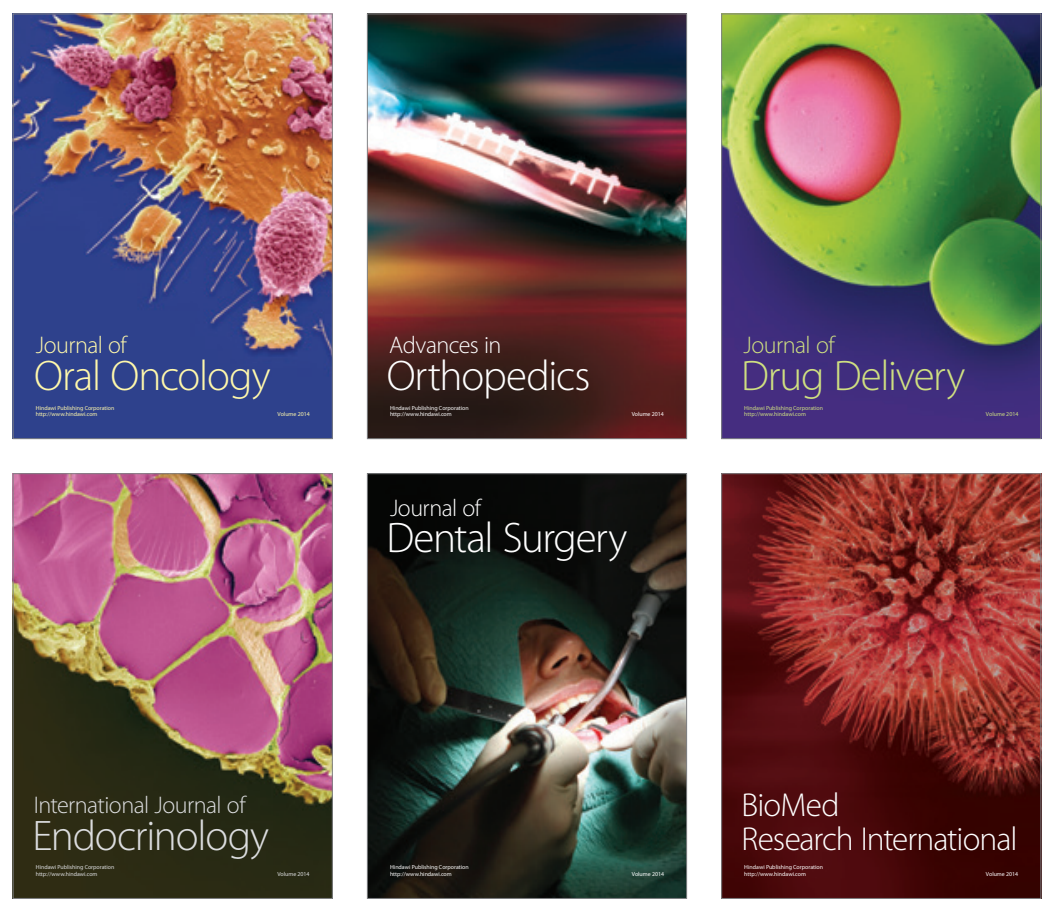

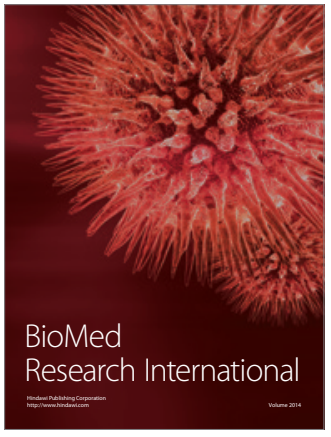

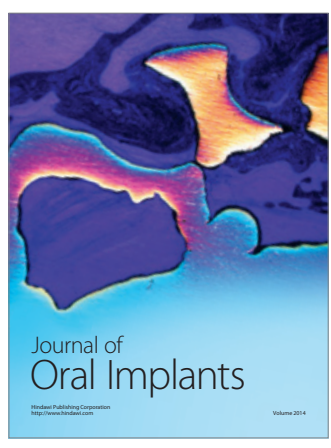
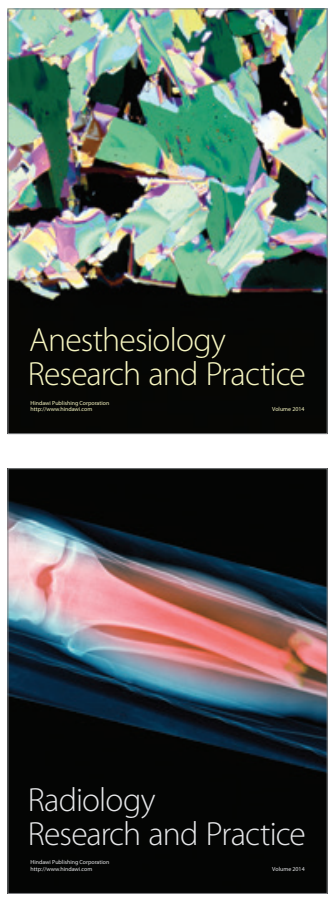